\title{
Semeando entusiasmos: a Reforma Orestes Guimarães em Santa Catarina (1910-1918)
}

\author{
Sowing enthusiasm: the Orestes Guimarães Reform in Santa Catarina \\ (1910-1918)
}

\section{Sembrando entusiasmos: la Reforma Orestes Guimarães en Santa Catarina (1910-1918)}

\author{
Uanessa Goes Denardi ${ }^{1}$ \\ Centro Universitário Municipal de São José, Professora na área de Pedagogia \\ Gladys Mary Ghizoni Teive ${ }^{2}$ \\ Universidade do Estado de Santa Catarina, Professora no Centro de Ciências Humanas e da \\ Educação
}

Resumo: Neste estudo teve-se como foco compreender a Reforma Orestes Guimarães em Santa Catarina efetivada nos anos 1910 até 1918. Para tanto, privilegiou-se como fonte os artigos do professor paranaense Raul Rodrigues Gomes publicados no jornal curitibano Diário da Tarde, em 1921, sobre a Reforma catarinense, analisando-os em uma interlocução, e por meio da metodologia de entrecruzamento de fontes, com os estudos da pesquisadora Gladys Mary Ghizoni Teive. Profundo admirador de Orestes de Oliveira Guimarães e de seus feitos no que tange à utilização da Pedagogia Moderna, Raul Gomes trouxe à tona, por intermédio de seus escritos, fatos e possibilidades de compreender a Reforma que elevou o Estado de Santa Catarina ao nível de modernização tão almejado e propagado pelos governantes e intelectuais no início do século XX, principalmente referente à criação dos Grupos Escolares e à remodelação das demais instituições escolares.

Palavras-chave: Orestes Guimarães. Raul Rodrigues Gomes. Pedagogia Moderna. Reforma Orestes Guimarães.

Mestre em Educação pela Universidade do Estado de Santa Catarina; Especialista em Gestão Educacional pela Universidade Estadual de Ponta Grossa.

2 Doutora em Educação pela Universidade Federal do Paraná; Mestre em Educação pela Universidade Federal de Santa Catarina. 
Abstract: This article focuses on the Orestes Guimarães Reformation in Santa Catarina, which was carried out in the years 1910 to 1918. For that, it was privileged as a source of the articles of the professor of Paraná Raul Rodrigues Gomes published in the newspaper Diário da Tarde in 1921 about the Reformation in Santa Catarina, analyzing them in an interlocution, and through the methodology of exchange of sources, with studies by researcher Gladys Mary Ghizoni Teive. A deep admirer of Orestes de Oliveira Guimarães and his unprompted achievements in Modern Pedagogy, Raul Gomes brought to the surface, through his writings, facts and publication possibilities, the Reformation that elevated the State of Santa Catarina to the level of modernization so modernized so longed and propagated by the rulers and intellectuals in the early twentieth century, mainly is not what is the creation of School Groups and remodeling of other school institutions.

Keywords: Orestes Guimarães. Raul Rodrigues Gomes. Modern Pedagogy. Orestes Guimarães Reformation.

Resumen: Este artículo tiene como foco comprender la Reforma Orestes Guimarães en Santa Catarina efectuada en los años 1910 hasta 1918. Para ello, se privilegió como fuente los artículos del profesor paranaense Raul Rodrigues Gomes publicados en el diario Diario da Tarde, en 1921, sobre la Reforma catarinense, analizándolos en una interlocución, y a través de la metodología de entrecruzamiento de fuentes, con los estudios de la investigadora Gladys Mary Ghizoni Teive. Profundo admirador de Orestes de Oliveira Guimarães y de sus hechos en lo que se refiere a la utilización de la Pedagogía Moderna, Raul Gomes trajo a la superficie, a través de sus escritos, hechos y posibilidades de comprender la Reforma que elevó el Estado de Santa Catarina al nivel de modernización tan anhelado y propagado por los gobernantes e intelectuales a principios del siglo $X X$, principalmente en lo que se refiere a la creación de los Grupos Escolares y remodelación de las demás instituciones escolares.

Palabras clave: Orestes Guimarães. Raul Rodrigues Gomes. Pedagogía Moderna. Reforma Orestes Guimarães. 


\section{INTRODUÇÃO}

No período da Primeira República, a escolarização passou a constituirse em uma exigência do processo de reajustamento social da população brasileira aos imperativos e territorialidades burguesas de organização social, transformando-se em projeto político do Estado. A República precisava de um novo homem, para uma nova era do "progresso e da ordem"; não qualquer homem, mas uma espécie muito particular - o "cidadão civilizado". Nesse sentido, cabia à instituição escolar a tarefa de civilizar e moralizar as crianças, disciplinando seus corpos e mentes para a "modernidade", e, para tal, fazia-se necessário o florescimento de uma nova cultura escolar e de um novo habitus pedagógico (TEIVE, 2008).

Não foi sem razão, portanto, que o Governador Vidal Ramos, na sua segunda gestão (1910-1914), empreendeu uma profunda reforma na instrução pública catarinense, buscando vencer o "atraso do ensino no Estado", circunscrito, segundo ele, na "fórmula carunchada e gasta do ler, escrever e contar", devido, principalmente, "à falta de mestres idôneos e a adopção de processos archaicos, considerados imprestáveis pela pedagogia moderna." (SANTA CATARINA, 191 la, p. 28).

Para esse empreendimento, foi contratado o professor paulista Orestes de Oliveira Guimarães, formado pela Escola Normal de São Paulo, uma vez que este Estado, com a sua Reforma da Instrução Pública iniciada em 1891, havia se convertido em modelo para todo o País. Essa Reforma seguia as novas ideias e os métodos de ensino considerados como os "mais modernos e aperfeiçoados" na Europa e nos EUA, os quais já vinham sendo desenvolvidos na "Escola Americana", fundada em 1871 no Estado de São Paulo, considerada uma escola revolucionária pela forma como encarava o aluno e sua relação com o conhecimento, já que se baseava nos preceitos da Pedagogia Moderna ao utilizar o método de ensino intuitivo e as lições de coisas. Para que Orestes Guimarães pudesse colocar em prática tal reformulação, foi criado o cargo de Inspetor Geral do Ensino de Santa Catarina, por ele ocupado até 1918, 
quando, a convite do Presidente da República, tomou posse do cargo de Inspetor Federal das Escolas Subvencionadas pela União.

Nessa mesma época, no Paraná, o jovem professor Raul Rodrigues Gomes, ${ }^{3}$ defensor da Pedagogia Moderna e que acompanhava e admirava a "semeadura" do bandeirante paulista no Estado vizinho, foi convidado para dirigir o Grupo Escolar Conselheiro Mafra e a Escola Complementar anexa na Cidade de Joinville, primeira instituição com a denominação de Grupo Escolar implantada pela Reforma de 1911. Em razão dessa designação, Raul Gomes teve maior contato e usufruiu das obras e feitos do professor Orestes Guimarães em Santa Catarina, passando a respeitar ainda mais o educador que, na sua concepção, fora uma espécie de "escola normal ambulante". ${ }^{4}$

Raul Gomes defendia, assim como Orestes Guimarães, que para que o País alcançasse a civilização e o progresso pretendidos se fazia necessário, com urgência, dissolver os arcaísmos e muito particularmente o atraso da instrução pública brasileira, seus programas e métodos, bem como o alto índice de analfabetismo da população brasileira e a desnacionalização de grande parcela da população (TEIVE, 2008, p. 72).

As ideias e feitos do "bandeirante paulista do ensino"5 na concepção e execução da Reforma da instrução pública catarinense impressionaram Raul Gomes de tal modo que ele, quando do seu regresso a Curitiba em 1921,

\footnotetext{
3 Raul Rodrigues Gomes (1889-1975) foi professor normalista, literato, funcionário postal e jornalista. Formou-se em Direito em 1935, tornando-se, anos depois, professor catedrático da Universidade Federal do Paraná (UFPR). Exerceu a profissão de professor universitário e secundário até a sua aposentadoria compulsória, em 1959. Importante intelectual paranaense, contribuiu para a criação de diversos centros de cultura em seu Estado, além de dirigir jornais e revistas de grande circulação em Curitiba entre os anos 1930 a 1960. Para saber mais sobre o intelectual paranaense, ler a dissertação de mestrado de Vanessa Goes Denardi intitulada Entre teses: uma travessia pelas representações do professor Raul Rodrigues Gomes sobre a Escola Nova (Paraná, décadas de 1920 e 1930) (DENARDI, 2017).

4 Expressão utilizada por Raul Gomes para designar Orestes Guimarães quando este ministrava aulas em todo o Estado de Santa Catarina para a preparação do magistério. Conferir em Gomes (1932, p. 1).

5 O fenômeno conhecido na historiografia brasileira como Bandeirismo Paulista do Ensino foi desencadeado pela Reforma da instrução pública do ensino paulista, iniciada em 1890, a qual, entre outros, implantou os grupos escolares. Essa experiência inovadora foi disseminada em todo o País por meio das chamadas "Missões de Professores Paulistas", da qual faziam parte normalistas com experiência docente e de gestão em grupos escolares, os quais eram contratados para realizarem reformas congêneres nos estados. Para saber mais sobre o Bandeirismo Paulista, ler os trabalhos de Souza (2011) e Teive (2014).
} 
planejou escrever um livro baseado em fatos e documentos oficiais cedidos pelo governador de Santa Catarina na época, Sr. Hercílio Luz, sobre como se operou a chamada Reforma Orestes Guimarães (COMO SE..., 1921). Tal obra, que seria dividida em três partes (I. a história da Reforma: o que era o ensino na Monarquia; II. os frutos da Reforma; e III. a nacionalização do ensino primário), não pôde ser localizada, o que nos leva a crer que o texto sequer tenha sido finalizado ou enviado a alguma editora. $\bigcirc$ que existe e fora publicado, de fato, é a primeira parte do tomo, que contém seis subtítulos, a saber: I. o que era o ensino na Monarquia; II. a situação do ensino na República; III. o ensino anterior à Reforma; IV. a necessidade da remodelação; V. o aparelho do ensino em 1907 a 191 l; e VI. a Reforma.

Dividido em formato de nove artigos, ${ }^{6}$ o texto foi veiculado no jornal curitibano Diário da Tarde nos dias 28 de novembro a 26 de dezembro de 1921, sobre os quais nos debruçaremos neste trabalho para analisar a Reforma Orestes Guimarães sob a ótica do jornalista e professor Raul Rodrigues Gomes, em um movimento de diálogo com outras fontes mediante uma análise metodológica documental, muito especialmente com o entrecruzamento com os estudos da professora e pesquisadora Dra. Gladys Mary Ghizoni Teive sobre o educador paulista e a sua atuação na educação catarinense, no período em que pregava e defendia a Pedagogia Moderna.

Nesse sentido, é mister destacar a importância e relevância dos periódicos para a História da Educação, já que a análise dessas fontes pode vir a contribuir para nossos conhecimentos em relação aos assuntos educacionais (SOUSA, 2002), bem como oferecer uma informação adicional para o entendimento de um contexto histórico, ainda que "os estudos históricos no Brasil têm dado pouca importância à imprensa como objeto de investigação, utilizando-se dela apenas como fonte confirmadora de análises apoiadas em outros tipos de documentação." (DE LUCA, 2005, p. 118).

Assim, o levantamento dos artigos jornalísticos contemplados neste trabalho ocorreu por meio de pesquisas realizadas na Biblioteca Pública do Paraná e na Hemeroteca Digital Brasileira, atentando-se para o fato de que

$\overline{6}$ Artigos digitalizados e disponíveis para consulta na Biblioteca Nacional Digital. 
"os jornais devem ser utilizados criticamente pelo historiador, para não correr o risco de se deixar levar pelo discurso da fonte e, consequentemente, realizar uma análise precipitada, acrítica e superficial (LAPUENTE, 2015, p. 1-2).

\section{A HISTÓRIA DA REFORMA: O QUE ERA O ENSINO NA MONARQUIA}

Ao expor como era o ensino no período monárquico, Raul Gomes propõe-se a contextualizar a situação do ensino primário não somente em Santa Catarina, mas em todo o País, de modo a fazer ver ao leitor a importância das reformas da instrução pública realizadas pelos diferentes Estados da federação a partir do final do século XIX e início do XX. Na sua opinião, o ensino durante a Monarquia era precário, não havia homogeneidade nos corpos docentes e os métodos e processos de ensino recaíam sempre sobre a capacidade de trabalho e os predicados intelectuais de cada professor. A escola não oferecia qualquer atrativo. Mobilidade ruim, paredes sombrias e carteiras ou classes sem a mínima correspondência com o tamanho e a idade dos alunos. Não havia mapas, nem quadros em um ambiente que infundia tédio e repulsão às crianças (GOMES, 1921 a).

○ regime era de soletração, tabuada e palmatória. As expressões "método intuitivo" e/ou "lições de coisas" ${ }^{7}$ não passavam de meras frases de efeito. Não havia entusiasmo pelo ensino, já que a escola nada oferecia de prático e, sobretudo, contínuo e duradouro. Santa Catarina, pequena unidade do Império, com população escassa e recursos financeiros exíguos (orçamento de 51 contos, em 1826, e de 415 contos, em 1886) padecia das consequências desse estado geral de coisas (GOMES, 1921 a).

A deplorável situação do ensino público catarinense não era, na sua opinião, desconhecida dos presidentes da província, e para comprovar essa percepção, Gomes transcreveu o seguinte excerto do relatório apresentado

\footnotetext{
A aplicação do método intuitivo partia de um ensino objetivo, real e pelo aspecto, denominado, portanto, de lições de coisas. Tal método era considerado o mais apropriado para espertar o desenvolvimento das faculdades intelectuais e morais e a aquisição do conhecimento.
} 
à Assembleia Provincial, pelo Presidente Dr. Adolpho de Barros Cavalcanti de Albuquerque, no ano 1866:

Não tem melhorado o estado pouco favorável da instrucção primaria na Província. Subsistem as causas de seu atraso; e enquanto não forem removidos por uma prudente reforma, na qual se deverão abranger o systema do ensino e ou condição do magistério, não é licito esperar melhoras que a simples acção do tempo está longe de poder operar. $\bigcirc$ Regulamento n. ${ }^{\circ} 382$ de 1854, incompleto e em muitas portas defeituosa precisa urgentemente ser alterado. [...] A fiscalização das escolas é a medida da mais reconhecida proximidade; mas deve ser constante para se tornar efficaz, e neste ponto há muito que melhorar no systema adaptado na Provincia. Carece ser augmentada e melhor definidas as atribuições do Director Geral e a sua acção immediata sobre o ensino, e os encarregados de semelhantes serviços [...]. Sobre estas bases geraes, pode a reforma trazer benefícios reaes á instrucção primaria da Província. (SANTA CATARINA, 1886, p. 16).

Desse modo, "tudo estava por fazer", e, para Raul Gomes, parte da solução do problema recaía na necessidade de uma nova metodologia, bem como no investimento na formação dos professores, já que havia escolas, mas estas não apresentavam eficácia, pois o corpo docente não dispunha de competência profissional adequada. Era preciso inovar, renovar, reestruturar, e Santa Catarina não podia se desviar dessa linha.

\section{A SITUAÇÃO DO ENSINO NA REPÚBLICA E A NECESSIDADE DE REMODELAÇÃO}

De acordo com Raul Gomes, se na Monarquia a Província demandava considerável parte de seus recursos para a difusão do ensino, na República o investimento deveria ser maior e surpreendente, haja vista que não se podia mais adiar a reforma do ensino e o combate aos males nacionais. Nesse viés, um dos primeiros administradores republicanos do Estado, o coronel Gustavo Richard, já havia sinalizado interesse em reformar a instrução 
pública catarinense segundo a Pedagogia Moderna, afirmação que pode ser corroborada no trecho de uma mensagem dirigida por Richard ao primeiro Congresso Legislativo em 1891:

Um dos ramos mais importantes do serviço público, que, a meu vêr, não tem dado o resultado que se esperava dos sacrificios feitos para conseguil-o - é a Instrucção Pública. Não entrarei em longas considerações sobre as causas que motivaram este estado anormal; vos direi simplesmente que, das minhas observações, cheguei a convencer-me que o mal é grande, provindo em parte de regulamentos confusos e deficientes, de certa frouxidão nos exames e, sobretudo, de certas conveniências políticas do antigo regimen, cujo resultado foi prover grande número de escolas com pessoal insufficientemente preparado, contribuindo, desta forma, para collocar a instruçção publica na decadencia em que se acha. Para levantar o ensino no abatimento em que jaz, seria de toda urgencia uma reforma profunda, e muito concorreria para isso a criação de uma Escola Normal, onde se preparassem candidatos aptos para o magisterio e conhecedores dos methodos mais adiantados da pedagogia moderna. (SANTA CATARINA, 1891, p. 12).

Com esses argumentos, também aludidos por Raul em seu artigo, pretendia-se demonstrar a emergência da reforma que anos mais tarde o Governador Vidal Ramos empreenderia sob o comando do professor Orestes Guimarães. Nesse viés, Teive (2008) afirma que o Governador Gustavo Richard tentou operar, entre os anos 1906 e 1910, certa modernização na Instrução Pública a exemplo do que estava sendo executado em São Paulo, porém, não obteve êxito. Em contrapartida, a aproximação com os reformadores paulistas possibilitou a contratação, em 1907, do Professor Orestes Guimarães para remodelar o Colégio Municipal de Joinville nos moldes dos primeiros grupos escolares paulistas.

A principal função de Orestes Guimarães, nesse seu primeiro comissionamento em Santa Catarina, era a de nacionalizar o currículo da citada escola, cujo alunado era, em sua grande maioria, de descendência alemã, assim como os professores. Os entraves que encontrou nessa tarefa na Cidade de Joinville foram de tal monta que Raul Gomes assim expressou: 
Orestes Guimarães chegou, 14 anos depois, a confessar-me que esteve a pique de desistir da empreitada que se lhe dava! Dizia ele, que, quando acceitara o contracto, suppunha que a sua tarefa consistiria, apenas, em remodelar methodos de ensino, numa escola de crianças que soubessem se exprimir, perfeitamente em português. Ao se lhe deparar, porém, a realidade desoladora quasi desesperou! Esteve de malas promptas para retornar à sua terra! (GOMES, 192lc, p. 2).

O novo programa organizado por Orestes Guimarães obedecia aos ditames da Pedagogia Moderna, do método de ensino intuitivo e das lições de coisas, bem como do nacionalismo. Seguindo os princípios da Pedagogia Moderna, ele prescrevia lições mais práticas que teóricas, "encaminhadas de modo que as faculdades das creanças sejam incitadas a um desenvolvimento gradual e harmonico." (SANTA CATARINA, 191 lb, p. 4). De acordo com Raul Gomes, ao final do segundo e último ano do comissionamento do professor Orestes Guimarães, a escola tornou-se modelar no que se referia à prática da Pedagogia Moderna e da ação nacionalizadora, e, após concluída a sua organização, Orestes Guimarães retornou a São Paulo, onde passou a dirigir o $1^{\circ}$ Grupo Escolar do Brás. Todavia, essa gestão ocorreu por pouco tempo, pois, em 1910, o Governador Vidal Ramos (1910-1914), decidido a modernizar a instrução pública catarinense, contratou Orestes Guimarães para empreender a Reforma. Segundo Vidal Ramos,

Tendo assumido o Governo com o firme propósito de empregar toda a energia de que me sinto capaz para demover a instrução popular do nível em que está foi um dos meus primeiros cuidados pedi ao ilustre Presidente do adiantado Estado de S. Paulo que pusesse á disposição do meu Governo o professor Orestes Guimarães escolhido por mim para auxiliar o trabalho de reorganização do ensino primário no Estado. (SANTA CATARINA, 191 la, p. 26).

O Governador Vidal Ramos resolvera, assim, aplicar em todo o Estado a orientação já vitoriosa em São Paulo e comprovada em Joinville, (re)contratando o professor Orestes Guimarães, com sua mulher, a também normalista Cacilda Rodrigues Guimarães, e um grupo de seis professores normalistas, todos 
paulistas, para auxiliá-lo na tarefa de tracejar "com extraordinária verdade, o quadro deplorável da organização pedagógica." (GOMES, 1921 b, p. 2).

\section{A REFORMA ORESTES GUIMARÃES}

Em mensagem proferida na sessão inaugural do Congresso Representativo do Estado, em 23 de julho de 191 1, o Governador Vidal Ramos chamou a atenção para a necessidade da reforma a fim de formar bons professores que seguissem as bases da Pedagogia Moderna, justificando que o segredo do êxito futuro residia na fundação de um novo tipo de escola, com certa fiscalização, dando à mocidade um corpo docente cheio de emulação.

Ao começar o trabalho como reformador, Orestes Guimarães tratou de providenciar diversas visitas às escolas de Florianópolis, acompanhado do chefe escolar Sr. Henrique Fontes, que "demorava-se, geralmente, das 10 horas da manhã às 17 horas, observando como os professores ensinavam, como decorriam todos os trabalhos escolares." (GOMES, 1921d, p. 1). Assim, o bandeirante paulista buscava a maior quantidade de indícios do que estava equivocado para planejar uma mudança de fato, ou, melhor, para ensinar o professorado catarinense a ensinar, e a bem ensinar. Dessa forma, a reforma da instrução pública foi iniciada em 191 1, na capital do Estado, pela remodelação da Escola Normal Catarinense. ${ }^{8}$

Destarte, em Decreto n. 585, de 19 de abril de 191 1, o Governo de Santa Catarina expediu um novo Regulamento Geral da Instrução Pública de acordo com as ideias de Orestes e baseado na Pedagogia Moderna, a saber:

\footnotetext{
$1^{\circ}$ ) organização da direção superior de ensino;

$\left.2^{\circ}\right)$ suppressão do Conselho Superior;

$3^{\circ}$ ) creação das inspectorias escolares, tendo em vista tornar uma realidade a fiscalização, sem o que não há ensino, embora haja escolas;
}

8 Sobre a reforma da Escola Normal Catarinense efetuada por Orestes Guimarães, consultar Teive
(2008). 
$\left.4^{\circ}\right)$ estabelecimento de categorias de escolas, de accôrdo com o ensino que o professor pode dar e não pela localidade em que estiver situada a escola;

$5^{\circ}$ ) instituição da estatística escolar, para creação de novas escolas;

$6^{\circ}$ ) uniformização da época da matrícula;

$7^{\circ}$ ) estabelecimento de normas práticas para a obrigatoriedade do ensino;

$8^{\circ}$ ) organização do novo plano para habitação de professores provisórios;

$\left.9^{\circ}\right)$ graduação do ensino que deve ser ministrado nos grupos e nas escolas isoladas;

$10^{\circ}$ ) estabelecimentos de normas liberaes para regularem o ensino privado. (SANTA CATARINA, 191 lc, p. 30).

A partir disso, Orestes Guimarães e sua mulher, Cacilda Guimarães, passaram a circular por todo o Estado de Santa Catarina demonstrando o novo método de ensino aos professores em exercício nos Grupos Escolares, Escolas Reunidas e Isoladas, movidos pelo pressuposto da Pedagogia Moderna de que seria "mais fácil compreender e executar o que se vê, do que o que se lê através de mil considerações e citações, sendo portanto inútil pensar em adquirir sem ter visto praticar." (TEIVE, 2008, p. 102).

Centrado na imitação de práticas pedagógicas modelares,

esse modo de aprender a ensinar garantiria, segundo Orestes Guimarães, a disseminação do método de ensino intuitivo ou lições de coisas bem como as práticas de organização da vida escolar dele decorrentes, por toda a rede escolar, com pouco investimento financeiro por parte do Estado. Concorreriam para isso a inspeção realizada pela Inspetoria Geral do Ensino e as regulamentações dela emanadas, como por exemplo a prescrição de que os professores das escolas isoladas localizadas nas proximidades de grupos escolares (a menos de $18 \mathrm{~km}$ ) eram obrigados a frequentá-los uma vez por mês, de modo a observarem o método seguido no ensino de algumas das disciplinas. A observação de práticas consideradas modelares, todavia, segundo o reformador, não deveria configurar-se numa cópia servil do método desenvolvido nos grupos escolares, mas numa maneira de "apreender os princípios da arte de ensinar e de aplicá-las inteligentemente na prática", tal como alertava E. White, autor do manual intitulado "A arte de ensinar". (TEIVE, 2008, p. 177). 
As Escolas Isoladas funcionavam em localidades distantes dos centros urbanos, com instalações improvisadas e precárias, e atendiam à população interiorana mediante um modelo de ensino multisseriado e monodocente (TEIVE, 2009). Já as Escolas Reunidas eram assim denominadas por serem, em virtude da quantidade de habitantes do local, a junção de duas ou mais escolas isoladas e que ainda não atendiam aos critérios para se tornarem Grupos Escolares, consideradas, portanto, semigrupos. ${ }^{9}$

Contudo, para o modelo paulista, o qual contava com simpatizantes como Raul Gomes, a reforma da instrução pública deveria ser iniciada pela reforma da Escola Normal e das Escolas Isoladas, seguida da implantação dos Grupos Escolares e das Escolas Complementares:

As novas formas de escolarização, assegurariam, conforme Orestes Guimarães, 'verdadeiro equilíbrio e seriação do ensino, isto é, o curso superior é o desenvolvimento do inferior ou aquele corolário deste', seguindo o pressuposto do método intuitivo de que o ensino deveria ser gradual e progressivo. Em vista disso, nas cidades em que fossem instalados os grupos escolares, o/a aluno/a após o término do seu curso primário de três anos na Escola Isolada poderia matricular-se no $4^{\circ}$ ano dos Grupos Escolares; os que concluíssem o curso primário nos grupos poderiam matricular-se nas escolas complementares (correspondente ao segundo grau do curso primário) e os egressos destas poderiam matricular-se no $3^{\circ}$ ano da Escola Normal, uma vez que o programa das Escolas Complementares era constituído dos dois primeiros anos da Escola Normal, divididos pelos três anos do curso complementar. (TEIVE, 2008, p. 97).

Nesse sentido, Teive (2008) salienta que esse tipo de sistema escolar estabelecia um considerável dualismo, haja vista que os Grupos Escolares, assim como as Escolas Complementares, seriam instalados apenas em centros urbanos de maior porte, restando para a maioria das cidades catarinenses apenas as Escolas Isoladas, que contavam com tempo de duração e programas diferenciados, além de professores com titulação bastante variada. Além disso,

9 Na Lei n. 1.044, de 14 de setembro de 1915, o Governador de Santa Catarina, coronel Felipe Schmidt, autoriza a criação de Escolas Reunidas em locais onde houvesse mais de duas escolas. Para saber mais, ler: Brasil (1915, p. 2). 
a Escola Normal, que era aberta aos egressos das Escolas Complementares e de Grupos Escolares, ficava sediada em Florianópolis, o que dificultava a ida dos estudantes do interior à instituição, sendo acessível apenas aos que podiam custear os estudos na capital do Estado. Ou seja, passou, assim, a existir uma espécie de atendimento escolar seletivo, fato esse não abordado ou ignorado nos escritos de Raul Gomes sobre a reforma catarinense.

Além da reforma na Escola Normal e Escolas Isoladas, Orestes Guimarães reestruturou também a Inspetoria Geral da Instrução Pública, órgão diretamente subordinado à Secretaria Geral do Estado e ao governador, modificando radicalmente "a forma de intervenção do Estado na gestão escolar, inaugurando uma forma inédita de relação social e de relação de poder entre a instituição escolar e o governo." (TEIVE, 2008, p. 101). Sob a sua batuta,

a instituição escolar passou a ser fortemente mediatizada pelas regras e normas propostas pela Inspetoria/Inspetor, as quais deveriam assegurar a interiorização/exteriorização pelos/as professores/as do conteúdo da reforma. $\bigcirc$ próprio reformador/inspetor gostava de inspecionar as escolas [...] em visitas que chegavam a durar cinco dias e, durante a sua estada [...] aproveitava para fazer a demonstração de como ensinar nos moldes do método de ensino intuitivo e das lições de coisas, uma vez que acreditava ser "mais fácil compreender e executar o que se vê, do que o que se lê através de mil considerações e citações". (GUIMARÃES, 1914, p. 158).

Com sua mulher, ele peregrinou pelo Estado organizando e dirigindo os primeiros Grupos Escolares, além de demonstrar aos professores dessas instituições e das Escolas Isoladas os pressupostos do método de ensino intuitivo e das lições de coisas. Conforme o seu próprio relato, no período de 1911 a 1915, ele e sua mulher, ${ }^{10}$ haviam demonstrado o novo método de ensino aos professores do interior do Estado mediante 2.252 aulas (TEIVE, 2008, p. 80-81).

\footnotetext{
10 Cacilda Rodrigues Guimarães aprendera o método de ensino intuitivo na Escola Modelo Caetano de Campos, dirigida pela professora norte-americana Márcia Priscila Browne. A influência de Miss Browne e de Horacio Lane, diretor da Escola Americana, fora decisiva na citada Reforma, razão pela qual Orestes Guimarães afirmava ser essa escola o "berço da reforma paulista. Sobre essa questão, sugere-se a leitura do trabalho de José Eliachim B Tapia e Ariovaldo Correa: Escola
} 
Porém, ainda havia um sério problema a ser enfrentado pelo reformador: a falta de normalistas. Sem desanimar, Orestes Guimarães fez uma severa seleção de professores, elegendo os que pareciam mais aptos e os que já revelavam ter vocação para o magistério, traquejando-os na arte de ensinar. Para Gomes (1921b), o bandeirante paulista era uma espécie de escola normal ambulante, capaz de transformar o mais incapacitado professor em um magnífico transmissor de conhecimento. Em relação a essa questão, em artigo publicado em 05 de dezembro de 1921, Raul Gomes afirmou que:

É necessário deixar bem saliente, porém, que o segredo do estrandoro, rápido, duradouro êxito da organisação da instrucção em Santa Catarina proveio da circumstancia de Orestes Guimarães preparar o professorado, ensinando- o a ensinar, não theoricamente, mas praticamente, com aulas ministradas. (GOMES, 1921 e, p. 1).

Orestes Guimarães com uma facilidade de surpreender com um desembaraço espantoso, pondo em função a sua competência e facilidade de expressão, ministrava aulas modelares, rigorosamente dentro do horário, bastando dizer, que, auxiliado de sua esposa, deu em 3 grupos, perto de 3.000 aulas, o que representa a media de 300 por mês em relação a cada estabelecimento. (GOMES, 192 lf, p. 1).

Dessa forma, após aprenderem a ensinar conforme os ditames da Pedagogia Moderna, os professores deveriam cumprir os seguintes deveres:

a) educar physica, moral e intellectualmente os alumnos das classes que regessem; b) não exercerem cargo estranho ao magisterio; c) não se ausentarem da sede do grupo, sem licença, mesmo durante as ferias; d) darem exemplos de moralidade, e polidez em seus actos, já na escola, já fora della; e) manterem suas classes a maxima disciplina conforme a orientação do director; f) seguirem

Americana de Florianópolis (1903-1911) publicado no livro Mosaico de Escolas, organizado por Dallabrida (2003). 
os methodos e processos de ensino recommendados pelo director; g) acharem-se rigorosamente no estabelecimento 15 minutos antes da hora marcada para a entrada dos alumnos para as aulas e 30 nos dias de fiscalização; h) exercerem a vigilância dos recreios e a dos alumnos reclusos; i) não abandonarem classes sem autorização do Director; j) não se occuparem em cousas ao ensino durante as horas de aula; k) executarem fielmente o programma e o horário, quando não fizessem offerecer por escripto os motivos; 1) responderem pelo andamento do ensino em suas classes, devendo ministrar ou recordar o programma dentro do anno lectivo. (GOMES, 192lf, p. 2).

Além da formação de professores, Orestes Guimarães precisou organizar os Grupos Escolares, provendo a essas instituições prédios padronizados com instalações especiais que priorizavam a organização, a higiene e a boa arquitetura para o fim pedagógico. Os prédios deveriam conter um museu escolar, um gabinete para o diretor e uma portaria. A matrícula era gratuita para ambos os sexos, e havia possibilidade de comparecer às aulas em trajes modestos e, até mesmo, descalço, acabando com as desculpas de que a pobreza era motivo para a infrequência escolar.

Feito isso, os Grupos Escolares passaram a seguir regras bastante rígidas de funcionamento: a carga horária diária era de cinco horas, com intervalo de 30 minutos, e nenhuma aula poderia exceder 40 minutos de duração. Esse programa, elaborado pelo governo, deveria ser seguido fielmente pelos diretores e professores das instituições escolares. Além disso, o método utilizado nos primeiros anos seria basicamente o intuitivo, e deveria haver disciplina em todos os aspectos e âmbitos: no recreio, no cumprimento dos deveres e, até mesmo, no material escolar. Para Gomes (192l g), todas essas exigências sempre tiveram rigorosa aplicação, fazendo com que a legislação catarinense, após a Reforma, não fosse uma "letra morta".

Assim, o pulso firme com que Orestes Guimarães liderou a remodelação do ensino em Santa Catarina e a forma como conseguiu reformar a instrução pública catarinense trouxe a muitos jovens educadores, como Raul Rodrigues Gomes, a esperança de um futuro em uma sociedade organizada e educada, em que a instrução passaria a ser o remédio único para todo mal da coletividade. Dessa forma, a semeadura do bandeirante paulista não gerou 
apenas frutos na educação catarinense, mas também entusiasmo para aqueles que acreditavam no poder do magistério.

Quando da morte de Orestes, em 1931, Raul Gomes utilizou, em artigo publicado no jornal curitibano O Dia, o epíteto "Pobre Orestes, Colossal Orestes", em alusão às palavras ditas por Carlyle a seu herói Oliver Cromwell. Justificou assim:

Pobre, porque arrebentou em Florianópolis de tanto viver pelos outros, por esta patria ingrata, por essa humanidade cruel um coração, um imenso, um extraordinário coração. Grande, porque todas as qualidades que ele trouxera do berço e as que adquirira pela cultura e pelo traquejo social, tudo isso concentrou num alto e limpido ideal confundido com a educação. Era da ponta do cabelo ás extremidades de qualquer parte de seu corpo uma personalidade saturada de educabilidade. (GOMES, 1932, p. 1).

E na conclusão desse mesmo artigo, Raul Gomes não poupou elogios e afirmou peremptória e apaixonadamente:

Miguel Couto pediu há pouco tempo que diariamente cada brasileiro pensasse na educação. Orestes Guimaraes fez mais que isso. Ele não teve, desde que saiu da escola normal, em São Paulo, nas vésperas da Proclamação da República, um só dia em que não fizesse uma grande ou uma pequena coisa pelo ensino. Homem de ação, ele não perdia um minuto de seus dias. Era uma maquina trabalhando constantemente pela educação do povo. Seu dia de serviço intenso era de perto de 20 horas. Creio que pouquíssimos padres, raríssimos militares, exíguos industriais no mundo inteiro consumirão ou consumiram tanta energia em prol de seu ideal ou seu oficio quanto Orestes Guimarães. Recompensas ele não as teve, nem buscava. Mas um prazer o encheu: Solitario quase nos primeiros tempos, escoltado duma altura em diante, chegou ao final de sua jornada já confundido com a multidão dos legionários da grande causa nacional! Foi por isso que me lembrei de Carlyle e vi reluzir entre mim e o nome do meu querido confrade e amigo, com quem colhi grande parte de meus entusiasmos pela educação. Nesta frase compungida, mas significativa: Pobre Orestes Guimarães, colossal Orestes Guimarães, como o inesxcedivel Carlyle disse de seu adorável herói - Cromwel: Pobre Cromwel - Grande Cromwel! (GOMES, 1932, p. 8, grifo do autor). 
Nesse sentido, Teive (2008) afirma que Orestes Guimarães, e sua Reforma, deixaram um importante legado, pois proporcionaram aos professores da rede pública as estruturas objetivas que, sob a ótica do reformador, deveriam garantir as condições para a produção e para a prática da nova estrutura pedagógica. Mediante a remodelação do sistema de ensino catarinense, ele buscou cumprir o que prometeu ao governo do Estado no sentido de modificar o sistema de pensamento, o habitus pedagógico da escola primária catarinense, harmonizando-a com as questões que orientaram e organizaram o pensamento no campo da educação escolar pública nos primeiros anos do século XX no Brasil. Orestes Guimarães replanejou a escola formadora de mestres e a escola primária, "criando condições para a consolidação de um sistema de ensino e a construção de um verdadeiro e orgânico sistema de pensamento, identificado com determinados interesses da sociedade brasileira no período republicano." (TEIVE, 2008, p. 194).

\section{CONSIDERAÇÕES FINAIS}

Ao fazer uso das fontes redigidas pelo professor paranaense Raul Rodrigues Gomes é possível perceber a enorme admiração que este mantinha por Orestes Guimarães, visto que em momento algum há críticas ao trabalho realizado pelo reformador paulista no Estado de Santa Catarina. A Reforma de 1911 realmente foi um feito de extrema importância e significância para a educação catarinense, colocando o Estado em evidência por meio da aplicabilidade da tão propalada Pedagogia Moderna.

Orestes Guimarães foi e é considerado um dos grandes vultos da instrução pública de Santa Catarina, não à toa Raul Gomes pretendeu publicar a obra sobre a Reforma baseada em fatos e documentos oficiais cedidos pelo Governador Hercílio Luz. A criação dos Grupos Escolares e a remodelação das demais instituições de ensino elevaram o Estado de Santa Catarina ao nível de modernização tão almejado pelos governantes e intelectuais de todo o território nacional. 
Dessa forma, (re)visitar as fontes históricas redigidas por Raul Gomes permite que sejam observados reflexos do movimento chamado Entusiasmo pela Educação, que pretendia, de maneira ufanista, resolver os problemas da educação brasileira. Nesse sentido, Orestes Guimarães era tido como expoente, primeiramente em seu trabalho em São Paulo e, logo após, com a obra efetuada no Colégio Municipal de Joinville, seguida da Reforma de Santa Catarina. Assim, Orestes Guimarães tornara-se, aos olhos do então jovem professor Raul Gomes, um semeador de entusiasmos no que tangia à modernização do ensino no País.

As demais fontes utilizadas para o entrecruzamento de informações, como os dados oficiais do Estado de Santa Catarina, mostram que o trabalho de Raul Rodrigues Gomes manteve, apesar da amizade que mantinha com o "personagem" principal da história, a fidedignidade dos fatos e dados, mostrando que Orestes Guimarães, como afirma Teive (2008), tornou-se uma figura central para a compreensão da forma de pensar o processo de escolarização e resgatar a historicidade de seu habitus pedagógico.

\section{REFERÊNCIAS}

BRASIL. Lei n. 1.044, de 14 de setembro de 1915. Dispõe sôbre tratamento excepcional para os alunos portadores das afecções que indica. Diário Oficial da União, Brasília, DF, 18 set. 1915.

$\mathrm{COMO} \mathrm{SE}$ FEZ a reforma do ensino em Santa Catharina. República, Florianópolis, p. 2, 18 set. 1921 .

\section{DALLABRIDA, N. (Org.) Mosaico de Escolas - Modos de Educação em}

Santa Catarina na Primeira República. Florianópolis: Cidade Futura, 2003.

DE LUCA, T. R. História dos, nos e por meio dos periódicos. In: PINSKY, C. B.

(Org.). Fontes Históricas. São Paulo: Contexto, 2005. p. $111-153$.

DENARDI, V. G. Entre teses: uma travessia pelas representações do professor Raul Rodrigues Gomes pela Escola Nova (Paraná, décadas de 1920 e 1930). 2017. Dissertação (Mestrado em Educação)-Universidade do Estado de Santa Catarina, Florianópolis, 2017.

GOMES, R. A História da Reforma: o que era o ensino na monarquia. Diário da Tarde, Curitiba, p. 2, 28 nov. 1921 a. 
GOMES, R. A História da Reforma: o que era o ensino na monarquia. Diário da Tarde, Curitiba, p. 2, 29 nov. 1921 b.

GOMES, R. A História da Reforma: o que era o ensino na monarquia. Diário da Tarde, Curitiba, p. 2, 02 dez. 1921 c.

GOMES, R. A História da Reforma: o que era o ensino na monarquia. Diário da Tarde, Curitiba, p. 2, 03 dez. 1921 d.

GOMES, R. A História da Reforma: o que era o ensino na monarquia. Diário da Tarde, Curitiba, p. 2, 05 dez. 1921 e.

GOMES, R. A História da Reforma: o que era o ensino na monarquia. Diário da Tarde, Curitiba, p. 2, 07 dez. $1921 \mathrm{lf}$.

GOMES, R. A História da Reforma: o que era o ensino na monarquia. Diário da Tarde, Curitiba, p. 2, 10 dez. $1921 \mathrm{~g}$.

GOMES, R. Pobre Orestes, Colossal Orestes. O Dia, Curitiba, p. 1 e 8, 06 jan. 1932.

GUIMARÃES, O. In: Relatório apresentado ao Exmo Sr. Coronel Vidal José de Oliveira Ramos, Governador do Estado pelo Secretário Geral Gustavo Lebon Regis. Florianópolis: Typographia da Livraria Central, 1914.

LAPUENTE, R. S. O jornal impresso como fonte de pesquisa: delineamentos metodológicos. In: ENCONTRO DA REDE ALFREDO DE CARVALHO (ALCAR), 10., 2015, Porto Alegre. Anais... Porto Alegre, 2015.

SANTA CATARINA. Relatório do Presidente Adolpho de Barros Cavalcanti de Albuquerque Lacerda à Assembleia Legislativa Provincial de Santa Catarina, em 1. ${ }^{\circ}$ de março de 1866. APESC, 1886.

SANTA CATARINA. Mensagem de abertura do primeiro Congresso Legislativo do Estado de Santa Catarina apresentada pelo vice-governador Coronel Gustavo Richard. Florianópolis, 29 set. 1891. Disponível em: <http://memoria.org.br/pub/meb000000517/rpescatarinal89lb/rpescatarinal89lb.pdf>. Acesso em: 20 ago. 2017.

SANTA CATARINA. Mensagem apresentada ao Congresso Representativo pelo Governador Vidal José de Oliveira Ramos. Florianópolis: Gab. Typ. D’O Dia, 191 la. 
SANTA CATARINA. Regimento Interno dos grupos escolares. Decreto n. 588, 22 abr. 191 1. Gab. Typ. D’O dia. Florianópolis, 191 lb. Acervo: Apesc. Disponível em: <https://repositorio.ufsc.br/xmlui/handle/123456789/122502>. Acesso em: 20 out. 2017.

SANTA CATARINA. Mensagem apresentada ao Congresso Representativo do Estado em 23 de julho de 1911 pelo Governador Vidal José de Oliveira Ramos. Florianópolis: Gab. Typ. D'O Dia, 191 lc.

SANTA CATARINA. Mensagem apresentada ao Congresso Representativo do Estado, em 23 de julho de 1912 pelo Governador Vidal José de Oliveira Ramos. Florianópolis: Gabinete de Typographia D'O Dia, 1912.

SOUSA, C. P. de. A educação pelas leituras: registros de uma revista escolar (1930/1960). In: CATANI, D.; BASTOS, M. H. C. (Org.). Educação em Revista: a imprensa periódica e a História da Educação. São Paulo: Escrituras, 2002.

SOUZA, R. F. O Bandeirismo Paulista no Ensino e a modernização da escola primária no Brasil: entre a memória e a história. Revista de Educação Pública, v. 20, p. 123-143, 2011.

TEIVE, G. M. G. Grupo escolar e governamentalidade liberal moderna: nova forma escolar, novos dispositivos, novas subjetividades. Campo Grande: Série-Estudos, 2009.

TEIVE, G. M. G. Professor Areão: experiências de um "bandeirante paulista do ensino" em Santa Catarina (1912-1950). Florianópolis: Insular, 2014.

TEIVE, G. M. G. Uma vez normalista, sempre normalista: cultura escolar e produção de um habitus pedagógico (Escola Normal Catarinense 1911 1/1935). Florianópolis: Insular, 2008.

Recebido em:: 29 de agosto de 2017 Aceito em:: 15 de dezembro de 2017

Endereço para correspondência: Rod. Amaro Antônio Vieira, 2623, Itacorubi, 88034-102, Florianópolis, Santa Catarina, Brasil; goes_vanessa@hotmail.com 